\title{
A INVASÃO DA SALA DE AULA PELA FILOSOFIA DA LINGUAGEM Contribuições da Hermenêutica Filosófica para o Ensino Jurídico
}

\section{Lucas de Melo Prado}

Mestre em Ciência Jurídica pela Universidade do Vale do Itajaí - Univali. Bacharel em Direito pela Universidade Federal do Piauí - Ufpi. Professor do curso de Direito da Faculdade Avantis, em Balneário Camboriú - SC. prado.lm@gmail.com

\section{Resumo}

0 presente artigo parte da ideia de crise do ensino jurídico a fim de discutir como o professor pode contribuir para a reforma da educação universitária por meio da alteração de suas práticas pedagógicas. Adota-se como marco teórico a Filosofia da Linguagem de Martin Heidegger e a hermenêutica filosófica de Hans-Georg Gadamer, apontando-se as contribuições que o giro linguístico oferece à Pedagogia. Defende-se que, para a formação de juristas críticos e autônomos, politicamente responsáveis e socialmente comprometidos com a concretização da Constituição e a realização dos direitos fundamentais, é necessária, ainda que não suficiente, a invasão da sala de aula pela Filosofia da Linguagem.

\section{Palavras-chave:}

Crise do ensino jurídico. Prática pedagógica. Filosofia da linguagem. Hermenêutica filosófica.

\section{THE INVASION OF CLASSROOMS BY THE PHILOSOPHY OF LANGUAGE \\ Contributions of the philosophical hermeneutics to legal teaching}

\section{Abstract}

This article starts from the idea of crisis in legal teaching in order to discuss how teachers can contribute to the renovation of university education through changes in their pedagogical practices. Martin Heidegger's philosophy of language and Hans-Georg Gadamer's philosophi- 
cal hermeneutics are adopted as the theoretical framework of this research, pointing out the contributions of the linguistic turn to pedagogy. It is argued that the invasion of classrooms by philosophy of language is necessary, even though not enough, to train critical and autonomous legal experts, politically responsible and socially committed to the concretization of the Constitution and the effectuation of human rights.

\section{Keywords:}

Crisis in legal teaching. Pedagogical practices. Philosophy of language. Philosophical hermeneutics.

\section{Sumário}

1 Introdução. 20 retrato estatístico da tragédia. 3 Aportes sobre a hermenêutica filosófica: temporalidade do dasein, círculo hermenêutico e fusão de horizontes. 4 A invasão. 5 Considerações finais. 6 Referências. 


\section{INTRODUÇÃO}

Em tempos de crise paradigmática, em que um passado moribundo não termina de morrer e um futuro nascente não termina de nascer (MORIN; KERN, 2000), a tendência moderna de especialização, fechando-se em si mesma, obnubila a visão do global e do essencial. A fragmentação das disciplinas e a diluição dos conteúdos impedem a compreensão do todo em suas relações de interdependência, interatividade e interretroatividade com seus respectivos componentes inseparáveis. Eis aí o desafio da complexidade (MORIN, 2003).

O positivismo jurídico, também padecente de hiperespecializaçáo e apostando na subjetividade do julgador, tem dificuldades em lidar com a ascensão do constitucionalismo dirigente, ${ }^{1}$ cuja ampla principiologia impóe a interação substancial de todos os componentes do sistema jurídico com a Constituição. No Brasil, a literatura jurídica utilizada nos cursos de Graduação, ainda apegada a esse paradigma subjetivista do positivismo normativista, não consegue fazer face ao desafio da complexidade, padecendo de uma anemia doutrinária, pautada por simplificações, esquematizações e padronizaçōes, limitando-se, via de regra, à reprodução de enunciados jurisprudenciais. Nos bancos da faculdade, o ensino manualesco e bancário ${ }^{2}$ reprisa soluçóes prontas e furta-se da responsabilidade de formar profissionais capacitados para lidar com os conflitos sociais e transindividuais enfrentados pela sociedade contemporânea - os quais demandam uma abordagem completamente diferente das lides patrimoniais individuais. Esse apego a uma epistemologia moribunda é defendido como se natural o fosse, o que torna ainda mais eficiente a ação de individualismos e solipsismos no âmbito jurídico, demonstrando o poder do habitus, teorizado por Pierre Bourdieu (1986), ou do senso comum teórico dos juristas, denunciado por Luís Alberto Warat (1982). (STRECK, 2007, 2014a, 2014b).

\footnotetext{
1 Sobre o constitucionalismo dirigente, $v$. Canotilho, 2001.

2 Sobre a concepção bancária da educação, na qual os educandos, meros depositários das narraçôes do educador, são instados a memorizar e repetir os conteúdos narrados, v. Freire, 1987, especialmente cap. 2.
} 
A reforma do ensino jurídico, nesse contexto, mostra-se como uma necessidade premente para a formação de juristas críticos, politicamente responsáveis e socialmente comprometidos com a concretização da Constituição e a realização dos direitos fundamentais. Imprescindível para superar o desafio da complexidade, a própria reforma reveste-se de características complexas, exigindo uma operacionalização de componentes diversos e interdependentes. Tais componentes incluem tanto questóes da alçada das próprias Instituições de Ensino Superior (IESs), como a matriz curricular, a literatura trabalhada e as formas de avaliação, quanto questões que extrapolam os domínios das IES tomadas individualmente, como os parâmetros (meramente) quantitativos de produção científica, o modelo das provas de concursos públicos e o (des)preparo dos alunos egressos do Ensino Básico.

Nessa perspectiva, alteraçôes no fazer docente estáo longe de serem suficientes para a consecuçáo da reforma do ensino jurídico, mas certamente são fatores necessários e até privilegiados para sua realização. Em proveito de tais alteraçóes, é indispensável o reconhecimento do atual momento de crise paradigmática, ${ }^{3}$ superando-se o paradigma subjetivista da consciência e desconstruindo-se a resistência da teoria do Direito à invasão da linguagem - resistência esta insistentemente evidenciada por Lenio Streck (2013, 2014a, 2014b).

Tendo por pano de fundo o paradigma da linguagem, o presente artigo busca analisar como a Filosofia hermenêutica e, em especial, a hermenêutica filosófica, podem contribuir para o desenvolvimento de uma prática docente transformadora e renovadora do ensino jurídico nas faculdades de Direito do Brasil.

Para tanto explicitar-se-á, inicialmente, as deficiências do ensino jurídico, tomando-se como parâmetro os resultados oficiais do Exame de Ordem, que busca identificar os requisitos mínimos para a inscrição do bacharel na Ordem dos Advogados do Brasil (OAB), e do Exame Nacional de Desempenho de Estudantes (Enade), que avalia as competências e habilidades dos egressos do ensino universitário, tanto no que se refere a conteúdos específicos da área jurídica quanto a conhecimentos gerais. Em que pese a pertinência das críticas dirigidas contra ambas as provas, as estatísticas daí provenientes são sintomáticas da crise por que passa o ensino jurídico e, desse modo, podem servir-lhe de retrato.

3 Sobre a estrutura das revoluçóes científicas com base em paradigmas, v. Kuhn, 2013. 
Na sequência, esclarecer-se-á no que consistem a temporalidade do Dasein, o círculo hermenêutico e a fusão de horizontes. Esses três conceitos, provenientes da Filosofia hermenêutica e da hermenêutica filosófica, são fundamentais para o argumento que se pretende desenvolver neste artigo.

Por fim, argumentar-se-á sobre como o processo de ensino-aprendizagem também não está imune à invasão da linguagem e, portanto, sobre como a prática docente pode tirar proveito do círculo hermenêutico e da fusão de horizontes, devidamente alicerçados na noçáo de temporalidade do Dasein.

\section{RETRATO ESTATÍSTICO DA TRAGÉDIA}

A taxa de reprovação entre os inscritos presentes na primeira fase do $\mathrm{X}$ Exame de Ordem Unificado foi de 71,9\%. Essa edição apresentou, até hoje (julho de 2015), o melhor desempenho dos bacharéis aspirantes a uma inscrição na OAB: foram $28,1 \%$ de aprovados. Em contrapartida, na edição com o pior desempenho dos examinados (III), a taxa de aprovação chegou a meros 12\%. (FUNDAÇÃO..., 2014) - ou seja, $88 \%$ dos alunos que se submeteram ao exame não conseguiram a nota mínima de aprovação. No XVI Exame de Ordem, sua última edição até a data de elaboração deste artigo, foram $20,9 \%$ de aprovados ( $79,1 \%$ de reprovados) (ORDEM..., 2015). O gráfico a seguir apresenta os índices de aprovação/reprovação dos examinados desde o I Exame de Ordem Unificado.

Gráfico 1 - Taxa de aprovação/reprovação no Exame de Ordem Unificado por ediçāo

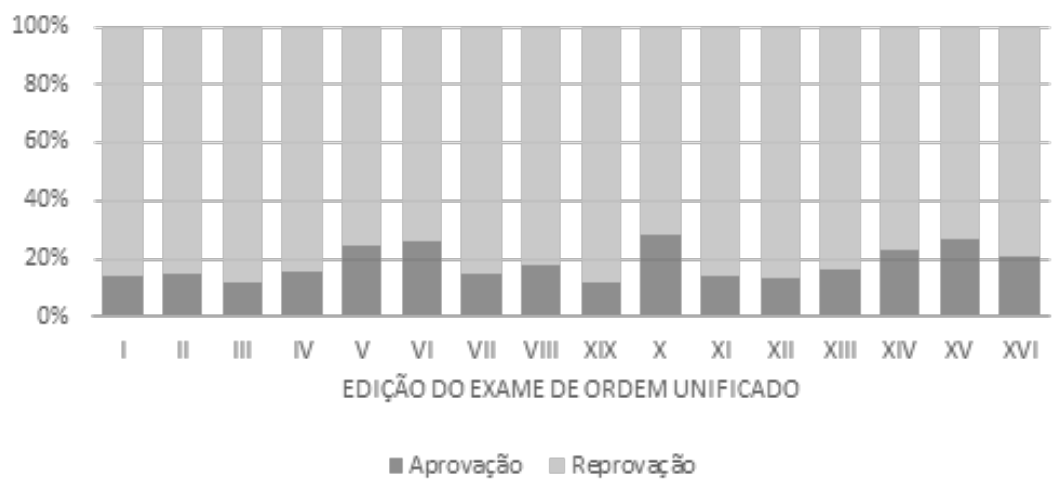

Fonte: FUNDAÇÃO..., 2014; ORDEM..., 2015. 
Os números são sintomáticos. Ano após ano, mais de $70 \%$ dos bacharéis egressos dos cursos de Direito espalhados por todo o Brasil mostram-se incapacitados, segundo a OAB, a exercer a advocacia. É bem verdade que o Exame de Ordem não está isento de críticas. As provas privilegiam a tecnicidade e a mera memorização de padróes de respostas pré-fabricados, afastando-se das habilidades e competências necessárias à compreensão crítica do Direito. Ainda assim, a baixa densidade epistêmica do exame náo justifica os projetos voltados a sua extinção. Antes, sinaliza para a necessidade de sua reestruturaçáo, o que inclui repensar o papel da Faculdade de Direito, que, em uma tentativa de se adaptar ao certame, acabou, em muitos casos, afastando-se do mister próprio da educação superior para se aproximar de um modelo de ensino resumido, acrítico e condensado, característico dos cursinhos preparatórios (STRECK, 2015; TRINDADE; ROSA, 2015).

Os efeitos desse ensino estandardizado ecoam também nos resultados do Exame Nacional de Desempenho de Estudantes (Enade) - o qual, distanciando-se do caráter tecnicista do Exame de Ordem, avalia, além de conteúdos específicos da área jurídica, os conhecimentos gerais dos alunos, bem como afere seu desempenho em relação às "habilidades para ajustamento às exigências decorrentes da evolução do conhecimento" e às "competências para compreender temas exteriores ao âmbito específico de sua profissão, ligados à realidade brasileira e mundial e a outras áreas do conhecimento" (INSTITUTO..., 2012, p. 5).

Segundo o relatório desse Instituto $(2009,2012)$ (v. Gráfico 2 a seguir), em 2009 metade dos 11.757 concluintes do curso de Direito presentes ao exame obtiveram nota inferior a 46,9 (de um máximo possível de 100). Mais de 65\% dos concluintes não conseguiram alcançar nota 60 . A nota máxima que um aluno obteve na prova foi 96,2. Em 2012 ( $v$. Gráfico 3), os resultados foram ainda piores. Metade dos 104.662 concluintes alcançaram nota inferior a 41,2 , e mais de $90 \%$ ficaram com nota inferior a 60. A nota máxima que um aluno conseguiu no exame foi 88 . 
Gráfico 2 - Distribuição das notas dos concluintes na prova - Enade/2009 - Direito

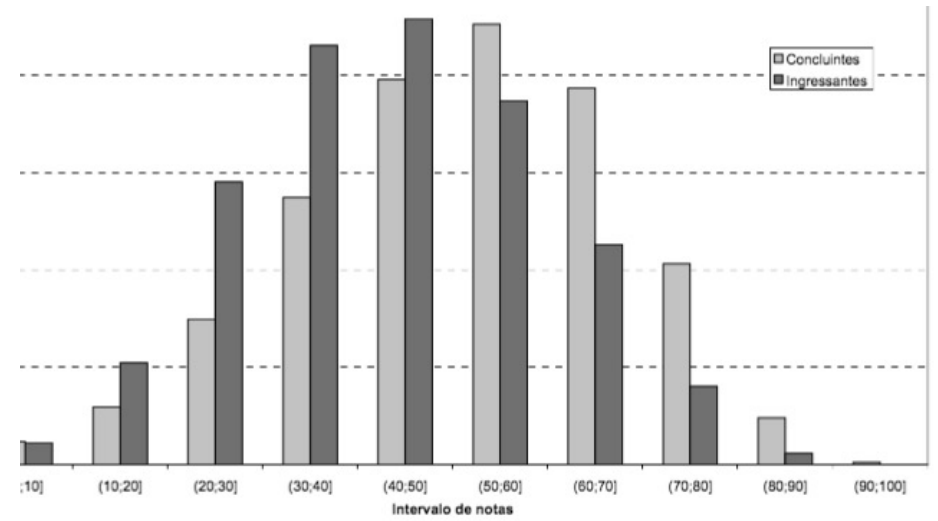

Fonte: INSTITUTO..., 2009, p. 29.

Gráfico 3 - Distribuição das notas dos concluintes na prova - Enade/2012 - Direito

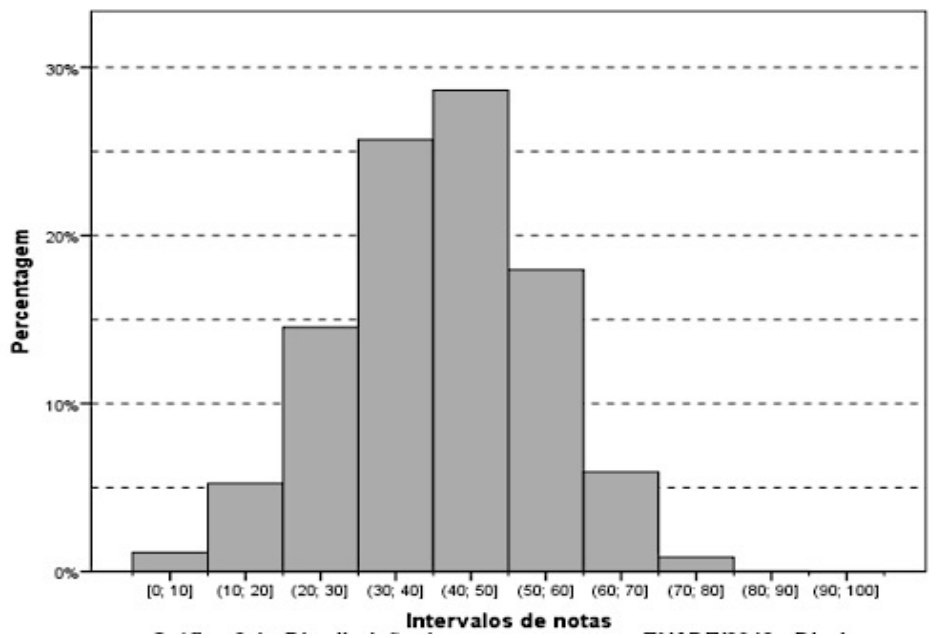

Fonte: INSTITUTO, 2012, p. 29.

Tendo por base os dados provenientes dos dois instrumentos anteriormente abordados (Exame de Ordem e Enade), o Conselho Federal da Ordem dos Advogados do Brasil (OAB) (2012) avalia os cursos de Direito do país a fim de conceder o selo de qualidade "OAB Recomenda". Com o desempenho flagrantemente cambaleante 
da maioria dos forma(n)dos que se submetem àqueles exames, não é de se estranhar que, dos 1.210 cursos jurídicos nacionais, apenas 89 (7,4\%) mereceram o selo “OAB Recomenda” em 2011.

Por trás desses números há uma realidade complexa, cuja multiplicidade de fatores conjuga-se em uma crise de natureza paradigmática, que atinge em cheio o fazer docente jurídico-universitário. ${ }^{4}$ Por um lado, as estatísticas são a extremidade de um iceberg que aponta para as deficiências do paradigma moderno assujeitador, ignorante diante da temporalidade do ser e de suas estruturas prévias de compreensão. Por outro, com a virada ontolinguística, a hermenêutica filosófica assoma no contexto de uma nova proposta paradigmática de reabilitação dos pré-conceitos, que reconhece a linguagem como condição de possibilidade dos processos de produção e transmissão do conhecimento, os quais se verificam a partir do círculo hermenêutico e da fusão de horizontes. A seguir, buscar-se-á esclarecer o sentido que esses conceitos adquirem na Filosofia hermenêutica de Martin Heidegger e na hermenêutica filosófica de Hans-Georg Gadamer, a fim de que possam servir de fundamento para se repensar as práticas docentes e a reforma do ensino jurídico.

\section{APORTES SOBRE A HERMENÊUTICA FILOSÓFICA: temporalidade do Dasein, círculo hermenêutico e fusão de horizontes}

A metafísica clássica "compreende o ser de maneira 'a-temporal', isto é como presença permanente" (GRONDIN, 1999, p. 7). Quer se esteja tratando do mundo das ideias ou do cosmo dos antigos ou, ainda, da divindade dos medievais, a procura pela essência das coisas na ontologia tradicional foi uma busca pela permanência que transcende a finitude, a mortalidade.

\footnotetext{
4 A título de exemplo, $v$. a análise de uma aula de Hermenêutica Jurídica em Streck et al., 2012.

5 Tradução livre. Texto original: “[...] comprendre l'être de manière 'a-temporalle', c'est-a-dire comme présence permanente."
} 
Em Ser e Tempo Martin Heidegger (2005) propóe uma nova ontologia, cuja tese essencial é a de que "a compreensão do ser se efetua sempre no horizonte do tempo"6 (GRONDIN, 1999, p. 9). E o ser, ao mesmo tempo indefinível, mas evidente por si mesmo, só pode ser compreendido, em sua temporalidade, a partir do ente que se questiona acerca do próprio ser (quem ou o que sou eu?). "Esse ente que cada um de nós somos e que, entre outras, possui em seu ser a possibilidade de questionar, nós o designamos com o termo pre-sença" (HEIDEGGER, 2005, p. 33, itálico no original).

O ser é compreendido, pois, a partir da pre-sença, tradução brasileira do termo alemáo Dasein - literalmente, o "ser-aî". E "a pre-sença [ou Dasein] sempre se compreende a si mesma a partir de sua existência" (HEIDEGGER, 2005, p. 39). Entende-se existência como "10) o modo de ser próprio do homem [Dasein]; 20) o relacionamento do homem consigo mesmo e com o outro [...]; $3^{\circ}$ ) relacionamento que se resolve em termos de possibilidade". Assim, "existir significa relacionar-se com o mundo, ou seja, com as coisas e com os outros homens" (ABBAGNANO, 2007, p. 466, 468, grifos no original).

A partir de Heidegger percebe-se que a compreensão está sempre inserida em um contexto relacional de temporalidade - contexto esse ao qual o Dasein, o ente humano capaz de questionar o seu próprio ser, estará sempre vinculado. Daí a impossibilidade do projeto iluminista de neutralidade e o esforço de Hans-Georg Gadamer (2005), discípulo de Heidegger, em reabilitar os pré-conceitos ${ }^{7}$ ou pré-juízos por meio de sua hermenêutica filosófica.

Com efeito, segundo Gadamer (2005), o Iluminismo (Aufkläkung) levou os pré-conceitos e a tradição ao absoluto descrédito. A ideia era a de se libertar de toda superstiçấo, pré-conceito e misticismo do passado, em prol de verdades cuja certeza seria garantida pelo estabelecimento racional de um método. Entende-se método como o “caminho 'mecânico' que pode ser feito e refeito através do uso de

6 Tradução livre. Texto oficial: "la compréhension de l'être s'effectue toujours dans l'horizon du temps."

7 O termo é traduzido para o português como "preconceito" ou "pré-conceito". Este artigo dá preferência à segunda grafia, a fim de não se confundir o termo técnico "pré-conceito", que, na Filosofia da linguagem é condição de possibilidade da compreensão, com o preconceito em seu sentido comum, vinculado a atitudes agressivas e discriminatórias, que rompem os laços interpessoais. As citaçóes diretas, no entanto, mantêm a grafia utilizada nos documentos originais. 
regras estabelecidas". Uma vez comprovado, tal caminho "pode ser (re)feito por qualquer outro sujeito que obterá os mesmos resultados, independente das contingências existenciais” (BRESOLIN, 2008, p. 69). Nesse diapasão, a razão, por meio de procedimentos metodológicos, teria o condão de anular os pré-conceitos e neutralizar a própria temporalidade do ser.

O giro provocado por Heiddeger, todavia, e o sentido temporal do ser do Dasein evidenciam que as próprias pretensôes da Aufklärung são determinadas por um pré-conceito básico de uma razão absoluta, que não deixa nenhuma possibilidade para a humanidade histórica. Por isso, assevera Gadamer (2005, p. 367, itálico no original):

A superação de todo preconceito, essa exigência global da Aufklärung, irá mostrar-se ela própria como um preconceito cuja revisão liberará o caminho para uma compreensão adequada da finitude, que domina não apenas o nosso caráter humano mas também nossa consciência histórica.

Destarte, superando-se o mito iluminista da neutralidade e partindo-se do caráter essencialmente temporal do ser, percebe-se que a própria razão está lançada na História, de forma que não se compreende fora do momento histórico. "Não é a história que nos pertence, mas somos nós que pertencemos a ela" (GADAMER, 2005, p. 367-368). Pela temporalidade do Dasein, os pré-conceitos, matizados negativamente pela Aufklärung, passam a ser condiçóes de possibilidade do próprio compreender.

Eis aí o ponto nevrálgico do processo de compreensão que, segundo a hermenêutica filosófica, dá-se pelo círculo hermenêutico: “os 'pré-conceitos' estão sempre implicados na compreensão" ${ }^{8}$ Em outras palavras, "não há compreensão sem pré-conceitos" (GRONDIN, 2016, p. 11). Todo processo de compreensão (de um texto, uma pintura, um filme, uma conversa ou uma aula) desenrola-se a partir de uma estrutura de pré-compreensão, projetada em antecipação pelo intérprete.

8 Tradução livre. Texto original: “'prejudices' are always at work in understanding”.

9 Tradução livre. Texto original: "there is no understanding without prejudices". 
Daí porque Gadamer (2005, p. 356) afirma que "quem quiser compreender um texto, realiza sempre um projetar". Abreviadamente, o círculo hermenêutico pode ser assim descrito:

Tão logo apareça um primeiro sentido no texto, o intérprete prelineia um sentido do todo. Naturalmente que o sentido somente se manifesta porque quem lê o texto lê a partir de determinadas expectativas e na perspectiva de um sentido determinado [pré-conceitos]. A compreensão do que está posto no texto consiste precisamente na elaboração desse projeto prévio, que, obviamente, tem que ir sendo constantemente revisado com base no que se dá conforme se avança na penetração do sentido (GADAMER, 2005, p. 356).

Nesse processo circular "compreensão e interpretação referem-se constitutivamente uma à outra" ${ }^{10}$ Enquanto "a compreensão denota a orientação básica do indivíduo à luz de antecipaçôes", ${ }^{11}$ a interpretação (Auslegung) "significa a elucidação esclarecedora dessas antecipaçóes”. ${ }^{12}$ (GRONDIN, 2016, p. 8, grifo nosso). Ora, se a interpretação é a explicitação, ou como chama Gadamer (2005, p. 404), o destaque das antecipaçóes e pré-conceitos que levaram à compreensão projetada pelo intérprete, então, diferentemente do que apregoava a Aufklärung, "não interpretamos para compreender (e, sim, compreendemos para interpretar)" (STRECK, 2014a, p. 252, itálicos no original).

Não basta, porém, apenas destacar os pré-conceitos que levaram à compreensão projetada. É preciso realizar um exame crítico, voltando-se o olhar para a própria coisa e diferenciando-se os pré-conceitos autênticos, que possibilitam a compreensão, dos inautênticos, que levam a mal-entendidos (GRONDIN, 2012). A pré-compreensão do intérprete, dessa forma, ao invés de ser eliminada, é "chamada à consciência a fim de ser posta à prova e questionada pelo texto"13 (GRONDIN, 2016, p. 10). É assim que a interpretação provoca constantemente a revisão do

\footnotetext{
${ }^{10}$ Tradução livre. Texto original: "understanding and interpretation refer constitutively to one another".

${ }^{11}$ Tradução livre. Texto original: "understanding means one's basic orientation in light of anticipations".

${ }^{12}$ Tradução livre. Texto original: "interpretation (Auslegung) signifies the clarifying elucidation of these anticipations".

${ }^{13}$ Tradução livre. Texto original: "The pre-understanding of the interpreter must not be eliminated, but brought to consciousness in order to be put to the test and be called into question by the text."
} 
projeto de compreensão do intérprete - não por meio de um "procedimento compreensivo", mas sim esclarecendo "as condiçóes sob as quais surge a compreensão" (GADAMER, 2005, p. 391).

Não obstante, como é possível distinguir os pré-conceitos autênticos dos inautênticos? Grondin (2012, p. 70, grifo nosso) lembra que Gadamer dirá com frequência: "é o recuo no tempo, a distância temporal, que permite fazer a triagem entre os bons e os maus pré-juízos". Na visão de Gadamer (2005), o tempo não é um obstáculo ou um abismo a ser transposto para que se possa compreender. Em outras palavras, a compreensão não depende da (ou não se esgota na) ocasião em que o autor produziu o texto ou do público que ele tinha em vista. O sentido da obra é determinado também pela situação histórica do intérprete. A obra sempre supera seu autor e, por esse motivo, a compreensão é sempre produtiva e não apenas reprodutiva. Daí porque a distância temporal deve ser elevada ao primeiro plano pela hermenêutica. "Trata-se de reconhecer a distância do tempo como uma possibilidade positiva e produtiva do compreender" (GADAMER, 2005, p. 393). É essa distância histórica ou temporal que faz com que os pré-conceitos sejam provocados pelo encontro com a tradição ${ }^{14}$ e saltem aos olhos para o exame crítico.

Esse encontro com a tradição depende tanto do horizonte de sentido do intérprete quanto do horizonte de seu objeto - entendido horizonte como "o âmbito de visão que abarca e encerra tudo o que pode ser visto a partir de um determinado ponto"15 (Gadamer, 2005, p. 399). Compreender a tradição requer um horizonte histórico. Todo intérprete, porém, que se desloca para a situação histórica do objeto interpretado, a fim de compreender seu horizonte de sentido, já possui, ele mesmo, seu próprio horizonte de sentido. Não se trata, pois, de uma neutralização do ho-

\footnotetext{
14 "A tradição representa o que não é 'objetivável' em um entendimento, mas que o determina imperceptivelmente." (GRONDIN, 2012, p. 69).

${ }^{15}$ Conforme Gadamer (2005, p. 400, 403), "aquele que não tem um horizonte é um homem que náo vê suficientemente longe e que, por conseguinte, supervaloriza o que lhe está mais próximo. Ao contrário, ter horizontes significa não estar limitado ao que há de mais próximo, mas poder ver além disso. Aquele que tem horizontes sabe valorizar corretamente o significado de todas as coisas que pertencem ao horizonte, no que concerne a proximidade e distância, grandeza e pequenez. [...] Ganhar um horizonte quer dizer sempre aprender a ver além do que está próximo e muito próximo, náo para abstrair dele mas precisamente para vê-lo melhor, em um todo mais amplo e com critérios mais justos".
} 
rizonte de sentido do próprio intérprete a favor daquele de seu objeto - inclusive porque a temporalidade do Dasein já aponta para a impossibilidade de uma tal neutralização. Tampouco se trata de ignorar o horizonte de sentido do passado, avaliando o velho com o olhar do novo. "Uma consciência verdadeiramente histórica sempre tem em vista também seu próprio presente, e quiçá de modo a ver as relaçóes corretas entre si mesma e o historicamente outro" (GADAMER, 2005, p. 403). Nesse sentido, todo compreender (e não apenas a compreensão do passado histórico) é um processo de fusão de horizontes. Nas palavras de Jean Grondin (2005, p. 403, itálicos no original):

A compreensão implementa assim uma "fusão" de horizontes, o do intérprete e o de seu objeto, na qual nem sempre se pode distinguir o que ressalta de um ou de outro. No caso da compreensão histórica, que constitui o caso-tipo para Gadamer, a compreensão presente de um texto ou de um autor antigo toma a forma de uma "fusão" entre o presente e o passado. O horizonte do passado se fusionaria assim com o do presente. Mas é claro que o escopo da fusão de horizontes transborda os limites da compreensão do passado. Ela opera também na compreensão do outro, de outras culturas e a fortiori na compreensão de si. ${ }^{16}$

Obviamente, o transbordamento de que trata Grondin atinge invariavelmente o processo de ensino-aprendizagem, calcado na possibilidade de compreensão de textos didáticos, do professor e dos demais alunos. Após o giro ontológico-linguístico nas linhas propostas por Heidegger e Gadamer, repensar a prática docente, o ensino e a universidade é necessariamente permitir que a docência seja invadida pela Filosofia da linguagem. No item a seguir, propor-se-á como os conceitos da hermenêutica filosófica antes trabalhados podem contribuir para renovar as práticas docentes e, consequentemente, para lidar com a crise em que se encontra atualmente o ensino jurídico no Brasil.

\footnotetext{
${ }^{16}$ Tradução livre. Texto original: "La compréhension met ainsi en œuvre une "fusion" d'horizons, ceux de l'interprète et de son objet, où on ne peut pas toujours distinguer ce qui relève de l'un ou de l'autre. Dans le cas de la compréhension historique, qui constitue de cas-type pour Gadamer, la compréhension présente d'un texte ou d'un auteur ancien prend la forme d'une "fusión" entre le présent et le passé. L'horizon du passé se "fusionnerait" alors avec celui du présent. Mais il est clair que la portée de la fusion des horizons déborde le cadre de la compréhension du passé. Elle est aussi à l'œuvre dans la compréhension d'autrui, d'autres cultures et a fortiori dans la compréhension de soi."
} 


\section{A INVASÃO}

Ante a complexidade da problemática da crise do ensino jurídico, que se traduz na multiplicidade de fatores aí implicados ( $v$. Introdução), a escolha da perspectiva a partir da qual se poderá pensar as possíveis saídas dessa crise já se apresenta como uma dificuldade a ser superada. À complexidade do problema segue-se a complexidade de panoramas possíveis de sua discussão.

Em conformidade com os parâmetros metodológicos estabelecidos para a presente pesquisa, toma-se o fazer pedagógico do docente como fator, se não suficiente, ao menos necessário para a melhora da educação jurídica superior. Para emplacar essa discussão adotam-se, como pontos de partida, as habilidades e competências que se espera que o formando de Direito desenvolva como resultado dos anos que passou nos bancos da faculdade. Tal perspectiva é coerente com os critérios adotados anteriormente para se aferir a (má) qualidade do ensino jurídico, com base no desempenho dos egressos dos cursos de Direito no Exame de Ordem e no Enade.

Adilson Gurgel de Castro (2000, p. 25) traça algumas linhas gerais a esse respeito, propondo oito itens que comporiam o perfil desejado de um formando de Direito. São eles:

$\left.1^{\circ}\right)$ permanente formação humanística, técnico-jurídica e prática, indispensável à adequada compreensão interdisciplinar do fenômeno jurídico e das transformaçóes sociais;

$2^{\circ}$ ) conduta ética associada à responsabilidade social e profissional;

$3^{\circ}$ ) capacidade de apreensão, transmissão crítica e produção criativa do Direito a partir da constante pesquisa e investigação;

4) capacidade para equacionar problemas e buscar soluçóes harmônicas com as demandas individuais e sociais;

$\left.5^{\circ}\right)$ capacidade de desenvolver formas judiciais e extrajudiciais de prevençáo e solução de conflitos individuais e coletivos;

$\left.6^{\circ}\right)$ capacidade de atuaçáo individual, associada e coletiva no processo comunicativo próprio ao seu exercício profissional; 
7o) domínio da gênese, dos fundamentos, da evolução e do conteúdo do ordenamento jurídico vigente; e

$8^{\circ}$ ) consciência dos problemas de seu tempo e de seu espaço.

Já uma leitura inicial das linhas gerais propostas por Castro para o perfil ideal do formando de Direito indica a insuficiência do atual ensino tecnicista, centrado na memorização de conteúdos e voltado para a formação de "respondedores de questóes" - diga-se de passagem, maus "respondedores de questóes", a julgar pelos resultados do Exame de Ordem e do Enade. Um ensino desenvolvido nesse modelo não consegue cumprir satisfatoriamente nem o primeiro item da lista proposta por Castro, tendo em vista as deficiências de formação humanística, reflexão ética, consciência social, espírito crítico e capacidade argumentativa.

Nesse contexto, a despeito da atuação (ou sua falta) dos canais institucionais, o que pode fazer o professor? Como pode o docente contribuir para a melhoria do ensino jurídico e para a formação de juristas críticos e autônomos, politicamente responsáveis e socialmente comprometidos com a concretização da Constituição e a realização dos direitos fundamentais?

Enquanto conceptualização dos caminhos da compreensáo, que está no cerne de qualquer processo de ensino-aprendizagem, a hermenêutica filosófica pode oferecer contribuiçóes valiosas para o enfrentamento dessas questóes. Isso porque o ensino tecnicista e bancário, cujos resultados denunciam sua ineficácia, sorve suas forças ainda de uma fonte iluminista, que ignora a revolução paradigmática da Filosofia da linguagem. Para renovar o fazer docente é imprescindível superar as crenças limitantes da Aufklärung. A reforma universitária somente será realmente transformadora quando conseguir realizar seu próprio giro linguístico, livrando-se do “pré-conceito contra os pré-juízos” (GRONDIN, 2012, p. 68).

Nesse diapasão, a renovação das práticas docentes deve passar pelo reconhecimento

1. da temporalidade do Dasein e das estruturas de pré-compreensão que isso implica;

2. do papel da interpretação e da distância histórica para a explicitação e o exame crítico dos pré-conceitos e

3. da construção da compreensão como uma fusão de horizontes de sentido. 
Considerar pedagogicamente esses três pontos é o que aqui se propôe chamar de invasáo da sala de aula pela Filosofia da linguagem, ${ }^{17}$ o que se explica a seguir.

Primeiramente, faz-se mister conscientizar-se de que insistir na neutralidade racional propagada pela Aufklärung é apostar em um mito, em uma ilusão, com alto potencial de aprofundar ainda mais a crise do ensino. É necessário, antes de tudo, (1) reconhecer a temporalidade do Dasein. Dessa maneira, o professor percebe que os estudantes não são caixas vazias, prontas para receberem o depósito de seus conhecimentos - como de há muito denuncia Paulo Freire (1987). Todo ser humano está inserido na historicidade e interpreta as informaçôes que recebe a partir de uma estrutura de pré-compreensão. Em uma sala com 30 alunos, por exemplo, a informação trabalhada será assimilada de 30 formas diferentes. Ignorar os pré-conceitos e pré-juízos trazidos pelos alunos para o processo de ensino-aprendizagem é desprezar elemento essencial para o desenvolvimento de estratégias eficientes de ensinagem e desconsiderar o aluno como sujeito ativo de sua própria aprendizagem.

Admitir o inexorável papel da pré-compreensão no processo de ensino-aprendizagem leva à percepção (2) do ofício capital da interpretação enquanto explicitação e exame crítico dos pré-conceitos. Aqui fica claro que o docente deve desempenhar um papel que vai bem além da mera exposição de conteúdos. É atribuição inarredável do professor estimular a autoanálise de seus alunos, a fim de que eles possam descobrir criticamente seus próprios pré-juízos, constatando o papel que esses desempenham em sua compreensão. Apenas por meio de uma interpretaçáo crítica de seus pré-conceitos os alunos são instados a adentrar no círculo hermenêutico, que lhes permitirá alcançar compreensôes mais autênticas do conhecimento apreendido.

Para tanto, deve-se abandonar o esquema de aulas expositivas, a favor de aulas dialogadas, nas quais o monólogo repetitivo é substituído pelo diálogo construtivo, centrado no aluno, despertando-lhe a reflexão crítica, conciliando teoria e prática e permitindo o enriquecimento mútuo entre alunos e entre alunos e professor (MELO FILHO, 2000, p. 40-41). Nessa mesma toada, o professor deve buscar

${ }^{17}$ Inspirada na expressão "invasão da filosofia pela linguagem”, repetidamente utilizada por Lenio Streck (2007, 2013, 2014a, 2014b). 
sempre diversificar suas estratégias de ensinagem, ${ }^{18}$ impelindo constantemente seus alunos a refletirem acerca das informaçóes que lhes chegam, inclusive adaptando suas compreensóes iniciais, quando fruto de pré-conceitos inautênticos.

Nesse ponto, o professor precisa estar consciente de que a historicidade do Dasein e a interpretação são inescapáveis - o que até pode lhe poupar boas doses de frustraçóes, uma vez que ele passa a aceitar que a compreensão dos alunos acerca dos assuntos trabalhados em sala nunca será exatamente a mesma que a sua própria. De fato, os alunos nunca irão encarar seu objeto de estudo a partir do horizonte de sentidos do professor. Pretender que os estudantes neutralizem seu próprio horizonte de sentido é um dos mitos iluministas derrubados pela Filosofia da linguagem e pela hermenêutica filosófica.

Dessa maneira, as estratégias diversificadas utilizadas em meio a aulas dialogadas, procurando encorajar os alunos a se embrenharem no círculo hermenêutico, têm como objetivo (3) promover a fusão entre o horizonte do docente e os diversos horizontes dos educandos. Nesse movimento, a reprodução do saber dá-se de maneira criativa e crítica, convidando o aprendiz a ser sujeito ativo e ator necessário da construção de seus conhecimentos e do desenvolvimento de sua compreensão dos fenômenos jurídicos. O resultado da fusão de horizontes é um aprendizado significativo, capaz de reformular os pré-conceitos inautênticos do discente, ao tempo em que se adapta ao seu universo socioprático.

O docente que adota estratégias que promovem o círculo hermenêutico e a fusão de horizontes também contribui para a formação de aprendizes autônomos, preparados para a realizar suas próprias pesquisas e investigaçóes. O indivíduo que, em sala de aula, aprende a destacar seus próprios pré-juízos, analisando sua autenticidade à luz do horizonte trazido pelo outro, capacita-se a fazer o mesmo com os textos e discursos com as quais venha a entrar em contato no futuro, inclusive fora da sala de aula.

Ademais, ao perceber que a construção do conhecimento é sempre um esforço intersubjetivo, até mesmo na solitude da apreciação de uma obra literária, o sujeito abre-se ao diálogo construtivo, à consideração das demandas das outras

${ }^{18}$ Sobre diferentes estratégias de ensinagem, $v$. Anastasiou e Alves, 2003. 
pessoas e da sociedade, bem como aos problemas de seu tempo e do local em que vive. A temporalidade e a historicidade do Dasein impulsionam o aluno ao estudo da evolução histórica dos institutos jurídicos, conscientizando-o do papel primordial da distância temporal para o processo de compreensão.

De maneira geral, a invasão da sala de aula pela Filosofia da linguagem permite trabalhar-se de maneira muito mais abrangente e satisfatória as habilidades e competências que se espera sejam desenvolvidas pelos discentes durante o curso de Direito. Obviamente, a renovação da prática pedagógica de um docente isolado não promove a necessária reforma universitária, que inclui a reestruturação do ensino jurídico. Para o docente comprometido com a qualidade da educação de seus alunos, todavia, a adoçâo da Filosofia da linguagem em seu fazer pedagógico mostra-se como uma alternativa com grande potencial para ser um diferencial significativo na formação do futuro jurista.

\section{CONSIDERAÇÕES FINAIS}

Há algo de enfermiço no reino da educação jurídica. O diagnóstico salta aos olhos quando os sintomas tomam a forma de números. Em que pesem os problemas estruturais do Exame de Ordem e do Enade, os resultados sofríveis obtidos nesses testes pelos egressos dos diversos cursos de Direito do país indicam alarmantemente o baixo nível dos juristas profissionais lançados anualmente no mercado de trabalho. Sáo traços de uma crise do ensino jurídico que acompanha a complexidade da crise paradigmática da própria modernidade.

A impossibilidade de se abordar todos os fatores que envolvem essa multifacetada questão forçou a escolha metodológica da presente análise pontual, centrada na prática docente e nas contribuiçóes da superação do paradigma subjetivista da consciência por meio da invasáo da sala de aula pela Filosofia da linguagem e pela hermenêutica filosófica.

Ao reconhecer a temporalidade do Dasein, o papel da interpretaçáo autocrítica no círculo hermenêutico e a construção intersubjetiva do conhecimento, por meio da fusão de horizontes, o docente vê-se obrigado a mudar seu fazer pedagógico. $\mathrm{O}$ monólogo cede lugar ao diálogo. A memorização dá lugar à reflexão. 
$\mathrm{E}$ a dependência cede lugar à autonomia. Com a adoção de novas estratégias de ensino, com vistas às estruturas de pré-compreensão próprias de cada aluno, a educação jurídica aproxima-se mais de seus objetivos pragmáticos de formação de profissionais tecnicamente competentes, criticamente conscientes, socialmente responsáveis e politicamente engajados.

É bem verdade que as alteraçôes no fazer docente estão longe de serem suficientes para a consecução da reforma do ensino jurídico, mas certamente são fatores necessários e até privilegiados para sua realização. Ainda que não receba o indispensável suporte institucional ou não seja acompanhado por seus colegas docentes, o professor que estimula seus alunos a penetrarem o círculo hermenêutico, por meio da interpretação de seus próprios pré-conceitos e pré-juízos, já representa um diferencial na formação do jurista, provendo-o dos meios necessários para se tornar sujeito ativo na construção autônoma de seu conhecimento.

\section{REFERÊNCIAS}

ABBAGNANO, N. Existência. In: Dicionário de filosofia. Tradução A. Bosi. 5. ed. rev. e ampl. São Paulo: Martins Fontes, 2007. Título original: Dizionario di filosofia.

ANASTASIOU, L. G. C.; ALVES, L. P. Estratégias de ensinagem. In: ANASTASIOU, L. G. C.; ALVES, L. P. (Org.). Processos de ensinagem na universidade: pressupostos para as estratégias de trabalho em aula. Joinville: Univille, 2003. p. 67-100.

BOURDIEU, P. La force du droit: éléments pour une sociologie du champ juridique. Actes de la Recherche en Sciences Sociales, v. 64, p. 3-19, sep. 1986. Disponível em: <http://www. persee.fr/web/revues/home/prescript/article/arss_0335-5322_1986_num_64_1_2335>. Acesso em: 17 out. 2015.

BRESOLIN, K. Gadamer e a reabilitação dos preconceitos. Intuito, Porto Alegre, n. 1, p. 63-81, jun. 2008. Disponível em: <http://revistaseletronicas.pucrs.br/ojs/index.php/intuitio/ article/viewFile/3671/3297>. Acesso em: 17 jun. 2015.

CANOTILHO, J. J. G. Constituição dirigente e vinculação do legislador: contributo para a compreensão das normas constitucionais programáticas. 2. ed. Coimbra: Coimbra Ed., 2001. CASTRO, A. G. Pela melhoria dos cursos jurídicos. In: ORDEM DOS ADVOGADOS DO BRASIL. OAB ensino jurídico: balanço de uma experiência. Brasília: Conselho Federal, 2000. p. 9-36. 
FREIRE, P. Pedagogia do oprimido. 17. ed. Rio de Janeiro: Paz e Terra, 1987.

FUNDAÇÃO GETÚLIO VARGAS. Exame de ordem em números. [S.1.], 2014. Disponível em: <http://www.oab.org.br/arquivos/exame-de-ordem-em-numeros-II.pdf>. Acesso em: 5 out. 2015 .

GADAMER, H.-G. Verdade e método I: traços fundamentais de uma hermenêutica filosófica. Tradução de F. P. Meurer. 7. ed. Petrópolis: Vozes, 2005. Título original: Warheit und Methode.

GRONDIN, J. Heidegger et le problème de la métaphysique. Dioti, v. 6, p. 163-204, 1999. Disponível em: <https:/www.academia.edu/9243753/Heidegger_et_le_probl?me_de_ la_m?taphysique>. Acesso em: 20 ago. 2015.

. La fusion des horizons: la version gadamérienne de l'adæquatio rei et intellectus? Archives de philosophie, [S.1.], tome 68, p. 401-418, 2005. Disponível em: <https://www. academia.edu/9240126/La_fusion_des_horizons._La_version_gadam?rienne_de_ladaequatio_rei_et_intellectus>. Acesso em: 20 ago. 2015.

. Hermenêutica. Tradução M. Marcionilo. São Paulo: Parábola, 2012. Título original: L'herméneutique.

. What is the hermeneutical circle? In: KEANE, C.; LAWN, C. (Org.). The Blackwell companion to hermeneutics. West Sussex, UK: Wiley-Blackwell, 2016. Disponível em: <https://www.academia.edu/13944229/What_is_the_hermeneutical_circle>. Acesso em: 28 dez. 2016.

HEIDEGGER, M. Ser e tempo. Tradução M. S. C. Schuback. 15. ed. Petrópolis: Vozes, 2005. Parte 1. Título original: Sein und Zeit.

INSTITUTO NACIONAL DE ESTUDOS E PESQUISAS EDUCACIONAIS ANÍSIO TEIXEIRA. Relatório sintese: Enade 2009 - direito. [S.1.], 2009. Disponível em: <http:// download.inep.gov.br/educacao_superior/enade/relatorio_sintese/2009/2009_rel_sint_direito.pdf>. Acesso em: 17 out. 2015.

. Relatório sintese: Enade 2012 - direito. [S.1.], 2012. Disponível em: <http://download.inep.gov.br/educacao_superior/enade/relatorio_sintese/2012/2012_rel_direito.pdf>. Acesso em: 17 out. 2015.

KUHN, T. A estrutura das revoluçôes cientificas. Tradução B. V. Boeira e N. Boeira. 12. ed. São Paulo: Perspectiva, 2013. Título original: The structure of scientific revolutions. 
MELO FILHO, A. Juspedagogia: ensinar direito o direito. In: ORDEM DOS ADVOGADOS DO BRASIL. OAB ensino jurídico: balanço de uma experiência. Brasília: Conselho Federal, 2000. p. 37-49.

MORIN, E. A cabeça bem-feita: repensar a reforma, reformar o pensamento. Tradução E. Jacobina. 8. ed. Rio de Janeiro: Bertrand Brasil, 2003. Título original: La tête bien faite.

MORIN, E.; KERN, A. B. Terra-pátria. Tradução P. A. N. Silva. 3. ed. Porto Alegre: Sulina, 2000. Título original: Terre-patrie.

ORDEM DOS ADVOGADOS DO BRASIL. OAB recomenda: indicador de educação jurídica de qualidade. Brasília: Conselho Federal, 2012. Disponível em: <http://www.oab. org.br/arquivos/pdf/Geral/Programa_OAB_Recomenda.pdf>. Acesso em: 18 out. 2015.

Exame de ordem. Brasília, 2015. Disponível em: <http://www.oab.org.br/servicos/ examedeordem>. Acesso em: 16 out. 2015.

STRECK, L. L. Hermenêutica e ensino jurídico em terrae brasilis. Revista da Faculdade de Direito UFPR, Curitiba, v. 46, p. 27-50, 2007. Disponível em: <http://ojs.c3sl.ufpr.br/ojs/ index.php/direito/article/view/13495/9508>. Acesso em: 16 out. 2015.

. O que é isto - decido conforme minha consciência? 4. ed. rev. Porto Alegre: Livraria do Advogado, 2013.

- Hermenêutica jurídica e $(m)$ crise: uma exploração hermenêutica da construção do direito. 11. ed. rev. atual. e ampl. Porto Alegre: Livraria do Advogado, $2014 \mathrm{a}$.

-Verdade e consenso: constituição, hermenêutica e teorias discursivas. 5. ed. rev. mod. e ampl. São Paulo: Saraiva, 2014b.

. O fim do exame da OAB, o olho do Eike e o juiz dirigindo o Porsche. Revista Consultor Jurídico, 26 fev. 2015. Disponível em: < http://www.conjur.com.br/2015-fev-26/ senso-incomum-fim-exame-oab-olho-eike-juiz-dirigindo-porsche>. Acesso em: 17 out. 2015.

et al. "Hermenêutica constitucional" e o senso comum teórico dos juristas: o exemplo privilegiado de uma aula na TV. Direitos Fundamentais \& Justiça, [S.1.], ano 6, n. 9, p. 237-261, abr./jun. 2012. Disponível em: <http://www.dff.inf.br/Arquivos/PDF_Livre/19_Dout_Nacional\%209.pdf>. Acesso em: 5 out. 2015.

TRINDADE, A. K.; ROSA, A. M. É preciso separar a academia da preparação para o exame de ordem. Revista Consultor Jurídico, 17 out. 2015. Disponível em: <http://www.conjur. com.br/2015-out-17/diario-classe-preciso-separar-academia-preparacao-exame-ordem>. Acesso em: 17 out. 2015. 
WARAT, L. A. Saber crítico e senso comum teórico dos juristas. Revista Sequência, Florianópolis, v. 3, n. 5, p. 48-57, 1982. Disponível em: <https://periodicos.ufsc.br/index.php/ sequencia/article/view/17121/15692>. Acesso em: 17 out. 2015.

Recebido em 16/5/2016

Aceito em: 8/7/2016 